\title{
Gorlin-Goltz syndrome: clinical findings in a Italian population and review of the literature.
}

Journal: Giornale Italiano di Dermatologia e Venereologia

Paper code: G Ital Dermatol Venereol-6609

Submission date: February 29, 2020

Article type: Letter to the Editor

Files:

1. Reply letter to comments on the manuscript

Version: 1

Description:

File format: application/vnd.openxmlformats-officedocument.wordprocessingml.document

2. Manuscript

Version: 3

Description: manuscipt

File format: application/vnd.openxmlformats-officedocument.wordprocessingml.document 


\section{Page 1 of 13}

Dear editor,

We have reduced the number of words as much as possible but we have added three references as recommended by the reviewers.

We have revised the manuscript according to the referees' comments and indicated the changes in red.

- We entered the abbreviation NBCCS to indicate Gorlin Goltz syndrome;

- We have included an updated reference regarding molecular findings (Gianferante DM et al. 2018) and review the test and reference list accordingly;

- We mentioned other case cohorts described in Italy;

- We changed the term "ailment shuttles";

- We changed the diagnostic criteria (Eyans DG, Farndon PA. Nevoid basal cell carcinoma syndrome).

- We changed "multicenter approach" in "multidiscipilinary approach";

- We changed the title.

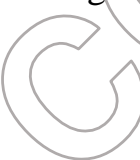


Title: Gorlin-Goltz syndrome: clinical findings in a Italian population and review of the literature.

\section{Contributors:}

Emanuele Miraglia*1, Alessandro Laghi ${ }^{1}$, Chiara Iacovino ${ }^{1}$, Antonietta Moramarco ${ }^{2}$, Sandra Giustini ${ }^{1}$.

\section{Affiliations:}

Department of Dermatology and Venereology, "Sapienza" University of Rône, Policlinico Umberto I, Viale del Policlinico, 155 Rome, Italy.

Department of Sense Organs, "Sapienza" University of Rome, Polidilicico Umberto I, Viale del Policlinico, 155 Rome, Italy.

\section{Corresponding author:}

Dr. Emanuele Miraglia: Department of Dermatology and Venereology, "Sapienza" University of Rome, Viaie del Policlinfor, N.155, 00161, Rome, Italy. Tel. +390649976968; Fax +390649976907; e-mait.emanuele.miraglia@hotmail.it.

Key words: Gorlin-Goltz syndrome - Nevoid basal cell carcinoma syndrome - PTCH. 
Dear editor,

Gorlin-Goltz syndrome or Nevoid basal cell carcinoma syndrome (NBCCS) is a rare inherited autosomal dominant genodermatosis, with nearly complete penetrance but variable expression. NBCCS results from mutations in the Patched 1 (PTCH1) gene (40\%-88\% of NBCES cases with higher estimates closer to $90 \%$ in more recent studies). Recently, mutations in suppressor of fused gene (SUFU) and PTCH2 have been found in patients with NBCCS. The estimated prevalence of the disease ranges between $1 / 57.000$ and $1 / 256.000$, with a male-to-fernale ratio of $1: 1$. The clinical features arise in the first, second, or third decades of life. ${ }^{1,2}$

This syndrome includes a wide spectrum of defects encompassing the skin, eyes, central nervous and endocrine system, and bones. Diagnosis is based on fulfilment of: two major diagnostic criteria and one minor diagnostic criterion or one major and three minor diagnostic criteria. Identification of a heterozygous germline PTCH1 or SUFU pathogenic variant oni molecular genetic testing establishes the diagnosis if clinical features are inconclusive. ${ }^{3}$

In this study we sought to in restigate clinical aspects in Itapan patients with NBCCS. We reviewed all clinical charts of 40 NBCCS patients followed by February 1983 to February 2020 at the "Sapienza" University of Rome, Italy Ail patients were investigated in a similar way with periodic evaluations that included dermatelogical, dental, ophthalmologic, gynecological and cardiological evaluation. Clinical examination included oral inspection, measurement of head circumference and interpupillary distance, examination of the skin for basal cell carcinomas (BCCs), and pits on the palms and soles. Radiographs of the chest, skull, spine, hands, pelvic (female) and teeth panorex were taken.

The age of patients ranged from 10 to 85 years, with a mean of 36.4 years. The follow-up period ranged from 1 to 30 years. Twenty-one (52.5\%) were female, and 19 (47.5\%) were male. A family history of NBCCS was present in 9/40 (22.5\%) patients. Of 40 patients, 24 underwent genetic testing for PTCH1. Of the 24 patients tested, 13 (54.1\%) were found to have a pathogenic PTCH1 mutation. BCCs were present in $87.5 \%$ of the patients $(80 \%$ of the BCCs were located in UV- 
exposed areas). The majority of the histologically examined BCCs were nodular. Palmar or plantar pitting was present in $60.7 \%$ of the patients. A calcification of the falx cerebri was found in $72.5 \%$ of the patients while odontogenic keratocysts (OKCs) were present in 67.5\%. Ocular manifestations were present in $85 \%$ of the patients (hypertelorism, strabismus, epiretinal membranes, congenital cataract, nystagmus, colobomas and myelinated optic nerve fiber layers). Other features were: macrocephaly $(67.5 \%)$, scoliosis $(35 \%)$, rib anomalie $(22.5 \%)$ and syndactyly $(2.5 \%)$. Of the 21 female patients, $47.5 \%$ had ovarian fibromas. In our patient cohort there was no medilloblastoma (Table 1).

The common manifestations in NBCCS are BCCs, OKCs of the jaw, congenial skeletal anomalies, palmar pits, and intracranial ectopic calcifications of the falx cerebri. More than 100 less common features have been identified. Multiple BCCs with early onset represent the most frequent clinical manifestation $(75 \%$ patients $>20$ years old and $90 \%$ patients $>40$ years old). In patients with NBCCS, BCCs are more likely to be multiple lesions, polymophic in nature, in either sex, and even areas not exposed to sunlight can be affected. They arent histologically different, but show a higher rate of recurrence after treatment than in aron-syndrome patients. Palmar or plantar pits (overall prevalence yaries from $70 \%$ to $90 \%$ ) are caused by a partial or complete absence of the corneum. They have a diameter $802-3 \mathrm{~mm}$ and a depth of 1-3 $\mathrm{mm}$. OKCs are rare benign neoplasms of the jaw with a $65 \%$ to $75 \%$ prevalence. They are generally found incidentally as a result of radiologic examinations and may be the first sign of the syndrome. Lamellar calcification of the falx cerebri is the most common radiological manifestation with a prevalence between $70 \%$ and $92 \%$; this calcification is not found in early childhood. Medulloblastoma, particularly the desmoplastic variant occurring in early childhood, is diagnosed in 5\% of NBCCS. Other features of the syndrome include craniofacial anomalies, skeletal anomalies, neurologic or central nervous system anomalies and other anomalies including genitourinary tract, cardiac and ophthalmologic anomalies. Tendency to tumors may be observed. 
This study was performed to delineate phenotypic characterization in patients with NBCCS. Four major studies investigated the clinical presentations of NBCCS. These studies were performed on populations in Japan, ${ }^{4}$ Australia, ${ }^{5} \mathrm{UK},{ }^{6}$ and USA. ${ }^{7}$ Some studies have also been conducted in Italy in smaller populations. ${ }^{8}$ The most significant finding of this study was the high frequency of BCCs and ovarian fibroma (Table 1).

To our knowledge, it represents the largest Italian study and one of the largest NBCCS cohorts published to date. In our case, unlike the other studies, all patients underwent multispecialist visits and instrumental investigations, in a similar way, in one center, every $3-6$ monthsobtaining more precise and accurate data.

A multidisciplinary approach is necessary in the diagnesis and treatmont in patients with NBCCS. Early diagnosis may allow patients to receive conservative treatment instead of complex therapies and render other family members aware of potential genetic risks. 


\section{REFERENCES}

1. Curatolo P, Miraglia E, Rotunno R, Calvieri S, Giustini S. Electrochemotherapy: a valid treatment for Gorlin-Goltz syndrome. Acta Dermatovenerol Croat 2013;21:132-3.

2. Gianferante DM, Rotunno M, Dean M et al. Whole-exome sequencing of neyoid basal cell carcinoma syndrome families and review of Human Gene Mutation Database PTCH1 mutation data. Mol Genet Genomic Med 2018;6:1168-80.

3. Evans DG, Farndon PA. Nevoid Basal Cell Carcinoma Syndrome. In: Adam MP, Ardinger HH, Pagon RA, Wallace SE, Bean LJH, Stephens K, Anemiya A, editorseneneviews® [Internet]. Seattle (WA): University of Washington, Seattle; 1993-202@2002 Jun 20.

4. Endo M, Fujii K, Sugita K, Saito K, Kohno Y, Miyashita T. Nationwide survey of nevoid basal cell carcinoma syndrome in Japan revealing the lowsrequency of basal cell carcinoma. Am J Med Genet A 2012;158A:351-7.

5. Shanley S, Ratcliffe J, Hockey A et al. Nevoidbasal cei carcinoma syndrome: review of 118 affected individuals. Am N Mied Genen 1994;50:232-90.

6. Kimonis VE, Goldstein AM, Pastakia B et al. Clinical manifestations in 105 persons with nevoid basal cell carcinoma syndrome. Am J Med Genet 1997;69:299-308.

7. Evans DG, Ladusans EX, Pimmer S, Burnell LD, Thakker N, Farndon PA. Complications of the naevoid basal celi carcinoma syndrome: results of a population based study. J Med Genet 1993;30:460-4.

8. Veronese F, Miglino B, Boggio P et al. Gorlin-Goltz syndrome: a case series from north Italy. Eur J Dermatol 2018;28(5):687-8. 
Page 7 of 13

1

2

3

4

5

6

7

8

9

10

11

12

13

14

15

16

17

18

19

20

21

22

23

24

25

26

27

28

29

30

31

32

33

34

35

36

37

38

39

40

41

42

43

44

45

46

47

48

49

50

51

52

53

54

55

\begin{tabular}{|c|c|c|c|c|c|}
\hline & This study & EVANS & KIMONIS & SHANLEY & ENDO \\
\hline Patients N. & 40 & 84 & 105 & 118 & 157 \\
\hline BCCs & $87.5 \%$ & $47 \%$ & $80 \%$ & $76 \%$ & $37.8 \%$ \\
\hline Calcification of falx cerebri & $72.5 \%$ & not assessed & $65 \%$ & $92 \%$ & $79.6 \%$ \\
\hline OKCs of the jaw & $67.5 \%$ & $66 \%$ & $74 \%$ & $75 \%$ & $86.3 \%$ \\
\hline Macrocephaly & $67.5 \%$ & not assessed & $49.2 \%$ & 80 & $26.5 \%$ \\
\hline Pitting & $60.7 \%$ & $71 \%$ & $87 \%$ & & $60.1 \%$ \\
\hline Ovarian fibroma & $47.5 \%$ & $24 \%$ & $17 \%$ & & $42.5 \%$ \\
\hline Hypertelorism & $47.5 \%$ & not assessed & accis & & $68.8 \%$ \\
\hline Scoliosis & $32.5 \%$ & not assessed & $310 \%$ & not assessed & not assessed \\
\hline Rib anomalie & $22.5 \%$ & not assessed & $38 \%$ & (c) $45 \%$ & $36.4 \%$ \\
\hline Syndactyly & $2.5 \%$ & notassessed & & $3 \%$ & $2.1 \%$ \\
\hline Medulloblastoma & $0 \%$ & & $4 \%$ & $1 \%$ & $3.3 \%$ \\
\hline
\end{tabular}

Table I. Comparison of clinical rnanifestations of the NBCecs. 
Title: Gorlin-Goltz syndrome: clinical findings in a Italian population and review of the literature.

\section{Contributors:}

Emanuele Miraglia*1, Alessandro Laghi ${ }^{1}$, Chiara Iacovino ${ }^{1}$, Antonietta Moramarco ${ }^{2}$, Sandra Giustini ${ }^{1}$.

\section{Affiliations:}

Department of Dermatology and Venereology, "Sapienza" University of Rône, Policlinico Umberto I, Viale del Policlinico, 155 Rome, Italy.

Department of Sense Organs, "Sapienza" University of Rome, Polidilicico Umberto I, Viale del Policlinico, 155 Rome, Italy.

\section{Corresponding author:}

Dr. Emanuele Miraglia: Department of Dermatology and Venereology, "Sapienza" University of Rome, Viaie del Policlinfor, N.155, 00161, Rome, Italy. Tel. +390649976968; Fax +390649976907; e-mait.emanuele.miraglia@hotmail.it.

Key words: Gorlin-Goltz syndrome - Nevoid basal cell carcinoma syndrome - PTCH. 
Dear editor,

Gorlin-Goltz syndrome or Nevoid basal cell carcinoma syndrome (NBCCS) is a rare inherited autosomal dominant genodermatosis, with nearly complete penetrance but variable expression. NBCCS results from mutations in the Patched 1 (PTCH1) gene $(40 \%-88 \%$ of NBCCS cases with higher estimates closer to $90 \%$ in more recent studies). Recently, mutations in suppressor of fused gene $(S U F U)$ and PTCH2 have been found in patients with NBCCS. The estimated prevalence of the disease ranges between $1 / 57.000$ and 1/256.000, with a male-to-fernale ratio of $1: 1$. The clinical features arise in the first, second, or third decades of life. ${ }^{1,2}$

This syndrome includes a wide spectrum of defects encompassing the skin, eyes, central nervous and endocrine system, and bones. Diagnosis is based on fulfilment of: two major diagnostic criteria and one minor diagnostic criterion or one major and three minor diagnostic criteria. Identification of a heterozygous germline PTCH1 or SUFU pathogenic variant on 0 rnolecular genetic testing establishes the diagnosis if clinical features are inconclusive. ${ }^{3}$

In this study we sought to in restigate clinical aspects in Itapan patients with NBCCS. We reviewed all clinical charts of 40 NBCCS patients followed by February 1983 to February 2020 at the "Sapienza" University of Rome, Italy, Ail patients were investigated in a similar way with periodic evaluations that included dermatelogical, dental, ophthalmologic, gynecological and cardiological evaluation. Clinical examination included oral inspection, measurement of head circumference and interpupillary distance, examination of the skin for basal cell carcinomas (BCCs), and pits on the palms and soles. Radiographs of the chest, skull, spine, hands, pelvic (female) and teeth panorex were taken.

The age of patients ranged from 10 to 85 years, with a mean of 36.4 years. The follow-up period ranged from 1 to 30 years. Twenty-one (52.5\%) were female, and $19(47.5 \%)$ were male. A family history of NBCCS was present in 9/40 (22.5\%) patients. Of 40 patients, 24 underwent genetic testing for PTCH1. Of the 24 patients tested, 13 (54.1\%) were found to have a pathogenic PTCH1 mutation. BCCs were present in $87.5 \%$ of the patients $(80 \%$ of the BCCs were located in UV- 
exposed areas). The majority of the histologically examined BCCs were nodular. Palmar or plantar pitting was present in $60.7 \%$ of the patients. A calcification of the falx cerebri was found in $72.5 \%$ of the patients while odontogenic keratocysts (OKCs) were present in 67.5\%. Ocular manifestations were present in $85 \%$ of the patients (hypertelorism, strabismus, epiretinal membranes, congenital cataract, nystagmus, colobomas and myelinated optic nerve fiber layers). Other features were: macrocephaly $(67.5 \%)$, scoliosis $(35 \%)$, rib anomalie $(22.5 \%)$ and syndactyly $(2.5 \%)$. Of the 21 female patients, $47.5 \%$ had ovarian fibromas. In our patient cohort there was no medulloblastoma (Table 1).

The common manifestations in NBCCS are BCCs, OKCs of the jaw, congenial skeletal anomalies, palmar pits, and intracranial ectopic calcifications of the laix cerebri. More than 100 less common features have been identified. Multiple BCCs with early onset represent the most frequent clinical manifestation ( $75 \%$ patients $>20$ years old and $90 \%$ patients $>40$ yecars old). In patients with NBCCS, BCCs are more likely to be multiple lesions, polymophic in nature, in either sex, and even areas not exposed to sunlight can be affected. They arenot histologically different, but show a higher rate of recurrence after treatment than in aron-syndrome patients. Palmar or plantar pits (overall prevalence yaries from $70 \%$ to $90 \%$ ) are caused by a partial or complete absence of the corneum. They have a diameter $60 \mathrm{e}-3 \mathrm{~mm}$ and a depth of 1-3 $\mathrm{mm}$. OKCs are rare benign neoplasms of the jaw with a $65 \%$ to $75 \%$ prevalence. They are generally found incidentally as a result of radiologic examinations and may be the first sign of the syndrome. Lamellar calcification of the falx cerebri is the most common radiological manifestation with a prevalence between $70 \%$ and $92 \%$; this calcification is not found in early childhood. Medulloblastoma, particularly the desmoplastic variant occurring in early childhood, is diagnosed in 5\% of NBCCS. Other features of the syndrome include craniofacial anomalies, skeletal anomalies, neurologic or central nervous system anomalies and other anomalies including genitourinary tract, cardiac and ophthalmologic anomalies. Tendency to tumors may be observed. 
This study was performed to delineate phenotypic characterization in patients with NBCCS. Four major studies investigated the clinical presentations of NBCCS. These studies were performed on populations in Japan, ${ }^{4}$ Australia, ${ }^{5} \mathrm{UK},{ }^{6}$ and USA. ${ }^{7}$ Some studies have also been conducted in Italy in smaller populations. ${ }^{8}$ The most significant finding of this study was the high frequency of BCCs and ovarian fibroma (Table 1).

To our knowledge, it represents the largest Italian study and one of the largest NBCCS cohorts published to date. In our case, unlike the other studies, all patients underwent multispecialist visits and instrumental investigations, in a similar way, in one center, every $3-6$ monthsobtaining more precise and accurate data.

A multidisciplinary approach is necessary in the diagnosis and treatmont in patients with NBCCS. Early diagnosis may allow patients to receive conservative treatment instead of complex therapies and render other family members aware of potential genetic risks. 


\section{REFERENCES}

1. Curatolo P, Miraglia E, Rotunno R, Calvieri S, Giustini S. Electrochemotherapy: a valid treatment for Gorlin-Goltz syndrome. Acta Dermatovenerol Croat 2013;21:132-3.

2. Gianferante DM, Rotunno M, Dean M et al. Whole-exome sequencing of neyoid basal cell carcinoma syndrome families and review of Human Gene Mutation Database PTCH1 mutation data. Mol Genet Genomic Med 2018;6:1168-80.

3. Evans DG, Farndon PA. Nevoid Basal Cell Carcinoma Syndrome. In: Adam MP, Ardinger HH, Pagon RA, Wallace SE, Bean LJH, Stephens K, Anemiya A, editors Genereviews® [Internet]. Seattle (WA): University of Washington, Seattle; 1993-2020.02002 Jun 20.

4. Endo M, Fujii K, Sugita K, Saito K, Kohno Y, Miyashita T. Nationwide survey of nevoid basal cell carcinoma syndrome in Japan reveating the low frequency of basal cell carcinoma. Am J Med Genet A 2012;158A:351-7.

5. Shanley S, Ratcliffe J, Hockey A et al. Nevoidbasal cei1 carcinoma syndrome: review of 118 affected individuals. Am NMied Genef 1994;50:232-90.

6. Kimonis VE, Goldstein AM, Pastakia B et al. Clinical manifestations in 105 persons with nevoid basal cell carcinoma syndíome. Am J Med Genet 1997;69:299-308.

7. Evans DG, Ladusans EX, Pimmer S, Burnell LD, Thakker N, Farndon PA. Complications of the naevoid basal celi carcinoma syndrome: results of a population based study. J Med Genet 1993;30:460-4.

8. Veronese F, Miglino B, Boggio P et al. Gorlin-Goltz syndrome: a case series from north Italy. Eur J Dermatol 2018;28(5):687-8. 
Page 13 of 13

1

2

3

4

5

6

7

8

\begin{tabular}{|c|c|c|c|c|c|}
\hline & This study & EVANS & KIMONIS & SHANLEY & ENDO \\
\hline Patients N. & 40 & 84 & 105 & 118 & 157 \\
\hline$\overline{B C C s}$ & $87.5 \%$ & $47 \%$ & $80 \%$ & $76 \%$ & $37.8 \%$ \\
\hline Calcification of falx cerebri & $72.5 \%$ & not assessed & $65 \%$ & $92 \%$ & $79.6 \%$ \\
\hline OKCs of the jaw & $67.5 \%$ & $66 \%$ & $74 \%$ & $75 \%$ & $86.3 \%$ \\
\hline Macrocephaly & $67.5 \%$ & not assessed & $49.2 \%$ & & $26.5 \%$ \\
\hline Pitting & $60.7 \%$ & $71 \%$ & $87 \%$ & & $60.1 \%$ \\
\hline Ovarian fibroma & $47.5 \%$ & $24 \%$ & $17 \%$ & $14 \%$ & $42.5 \%$ \\
\hline Hypertelorism & $47.5 \%$ & not assessed & & 607 & $68.8 \%$ \\
\hline Scoliosis & $32.5 \%$ & not assessed & $31 \%$ & not (essessed & not assessed \\
\hline Rib anomalie & $22.5 \%$ & not assessed & $38 \%$ & (0) $45 \%$ & $36.4 \%$ \\
\hline Syndactyly & $2.5 \%$ & notassessed & & $3 \%$ & $2.1 \%$ \\
\hline Medulloblastoma & $0 \%$ & & $4 \%$ & $1 \%$ & $3.3 \%$ \\
\hline
\end{tabular}

Table I. Comparison of clinical rnanifestations of the NBCC8. 